LEADING ARTICLE

\title{
Hepcidin and its role in iron absorption
}

\author{
K J Robson
}

Maintaining the correct iron balance is crucial to good health. Disorders of iron homeostasis have a global distribution. As iron is not actively excreted by the body, understanding the role of proteins involved in regulating iron uptake is essential to our understanding of disease involving iron homeostasis. Over the past 10 years, major advances have been made in understanding the genetics of iron metabolism and this has led to identification of a number of new proteins, including hepcidin, involved in iron homeostasis.

Correspondence to: Dr K J Robson, Weatherall Institute of Molecular Medicine, MRC Molecular Haematology Unit, John Radcliffe Hospital, Oxford, OX3 9DS; kathryn.robson @molecular-medicine. oxford.ac.uk

Accepted for publication 10 December 2003
M aintaining the correct iron balance is crucial to good health. Non-haem proteins and haem synthesis require the presence of iron. Disorders of iron homeostasis, both iron deficiency anaemia and iron overload, have a global distribution. As iron is not actively excreted by the body, understanding the role of proteins involved in regulating iron uptake is essential to our understanding of diseases involving iron homeostasis. Over the past 10 years, major advances have been made in understanding the genetics of iron metabolism and this has led to identification of a number of new proteins involved in iron homeostasis (reviewed by Fleming and Sly ${ }^{1}$ and Knutson M, WesslingResnick ${ }^{2}$ ).

Clement Finch, in his review in 1994 on regulators of iron balance in humans, described the characteristics of the store and erythroid iron regulators. ${ }^{3}$ This was based on physiological observations. The store regulator is most probably the peptide hepcidin. The model predicted that the store regulator would regulate iron uptake from the proximal cells of the duodenum. ${ }^{3}$ On a daily basis, the store regulator would increase iron uptake until there were sufficient iron stores for erythropoiesis. ${ }^{3}$ To prevent iron overload, a feedback mechanism has to be invoked. It is essential that this uptake process is tightly regulated because mammals lack a means of excreting iron. In mammals, iron is lost through the sloughing of cells, and in females also through menstruation and childbirth. The store regulator therefore regulates iron in the same way that a room thermostat maintains a constant temperature. The erythroid regulator on the other hand is involved in situations where there is a larger requirement for iron. The predicted location for the erythroid regulator is bone marrow because it is this tissue that is highly sensitive to iron stores. ${ }^{3}$

Several groups independently discovered hepcidin. Two groups found hepcidin while they
Gut 2004;53:617-619. doi: 10.1136/gut.2003.027631

were identifying novel antimicrobial peptides. Krause et al described a peptide that was synthesised by the liver that they called liver expressed antimicrobial peptide 1 (LEAP-1). ${ }^{4}$ Park et al identified a peptide they called hepcidin (hepatic bactericidal protein) in urine. ${ }^{5}$ Hepcidin mRNA expression is almost entirely restricted to the liver, with low levels also being found in the intestine, stomach, colon, lungs, and heart. ${ }^{56}$ The human hepcidin gene (HAMP) comprises three exons and maps to the long arm of chromosome 19 (19q13). ${ }^{5}$ The human gene encodes a prepropeptide of 84 amino acids. ${ }^{5}$ The signal peptide is cleaved to give the 60 amino acid form prohepcidin and this is further processed to give the 25 amino acid form hepcidin that is found both in blood ${ }^{4}$ and urine. ${ }^{5}$ Hepcidin is evolutionarily conserved; hepcidin genes have been found in fish. ${ }^{7}$ Eight of the 25 amino acids in hepcidin are cysteine residues. The 25 amino acid form has both antibacterial ${ }^{5}$ and antifungal activities, ${ }^{4}$ making hepcidin a member of the family of cysteine rich, cationic, antimicrobial peptides which includes the defensins. Members of this family of peptides have been shown to be involved in inflammation. Hepcidin has been shown to be a type II acute phase protein. ${ }^{8}$

\section{"The role of hepcidin in iron homeostasis was revealed by two French groups working independently"}

The role of hepcidin in iron homeostasis was revealed by two French groups working independently. Pigeon et al isolated the murine hepcidin gene using a differential screening approach. ${ }^{6}$ They identified hepcidin because this mRNA was increased under conditions of dietary iron loading. Nicolas et al identified the murine hepcidin gene as having a role in iron homeostasis totally serendipitously. ${ }^{9}$ In generating USF2 null mice they accidentally removed the neighbouring hepcidin genes. ${ }^{9}$ These mice spontaneously became loaded with iron and the pattern of iron loading mimicked that seen in hereditary haemochromatosis (HH). ${ }^{9}$ That hepcidin rather than USF2 was involved in iron homeostasis was confirmed when mice transgenic for hepcidin were produced and were severely anaemic. ${ }^{10}$ There are two hepcidin genes in mice ${ }^{69}$ but only one in humans. ${ }^{5}$ Loss of functioning hepcidin genes in mice was associated with raised serum iron, decreased reticuloendothelial iron stores, and increased intestinal iron absorption. ${ }^{9}$

Abbreviations: $\mathrm{HH}$, hereditary haemochromatosis 
Administration of lipopolysaccharide, a classic inducer of the acute phase response, results in increased hepcidin expression. ${ }^{11}$ Anaemia induced by haemolysis or phlebotomy results in reduced hepcidin expression ${ }^{11}$ which is also observed as a response to hypoxia. ${ }^{11}$ These results provide the necessary link between iron homeostasis and anaemia of chronic disease. Anaemia of chronic disease is poorly understood and is found in patients with a broad spectrum of diseases, including viral and bacterial infections, malignancies, and rheumatological complaints. Such conditions exhibit a blunted erythropoietin response by erythroid precursors, decreased red blood cell survival, and abnormalities in both iron absorption and retention of iron by macrophages, restricting the availability of iron to erythroid precursors in the marrow. This has been demonstrated in a specific set of patients with large hepatic adenomas who have a severe refractory anaemia that resolves once the adenomas are removed. ${ }^{12}$ In anaemia of chronic disease, there is a decrease in circulating iron, increased reticuloendothelial iron, and decreased intestinal iron absorption, while the reverse is true for haemochromatosis. Bridle et al demonstrated that hepcidin mRNA levels in the livers of patients with $\mathrm{HH}$ were inappropriately low with respect to their iron stores. ${ }^{13}$ Further work by the group of Stremmel demonstrated a link between transferrin saturation and hepatic hepcidin expression in patients with $\mathrm{HH} .{ }^{14}$ Hepcidin levels are inappropriately low in relation to plasma ferritin levels. ${ }^{8}$ The role of hepcidin in haemochromatosis was further confirmed when two families presenting with juvenile haemochromatosis, unlinked to the previously identified locus on chromosome 1, were found to have either a nonsense mutation in exon 2 or a frameshift mutation at the end of exon $2 .{ }^{15}$ Both of these mutations result in failure to synthesise hepcidin as this is entirely encoded by exon 3. Very recently, Merryweather-Clarke et al demonstrated a synergy between mutations in hepcidin and HFE resulting in haemochromatosis. ${ }^{16}$ The severity of the mutation in hepcidin determines whether the patient has juvenile or adult onset haemochromatosis. In a mouse model for haemochromatosis, constitutive expression reverses iron loading. ${ }^{17}$ In Hfe deficient mice there are alterations in expression of the homologues for ferroportin/IREGl, hepcidin, and the duodenal ferric reductase DCYTB. ${ }^{18}$ (For more details on the role of hepcidin as a key regulator in iron metabolism and as a mediator in the anaemia of inflammation see the review by Ganz ${ }^{19}$.)

\section{"In anaemia of chronic disease, there is a decrease in circulating iron, increased reticuloendothelial iron, and decreased intestinal iron absorption, while the reverse is true for haemochromatosis"}

Therefore, to understand both the role of hepcidin in modifying expression of iron uptake in patients with haemochromatosis and its involvement in patients suffering from anaemia of chronic disease, it is important to be able to quantify circulating levels of pro-hepcidin and hepcidin. Thus far, measurement of hepcidin has been limited to a reverse transcription step and amplification using the polymerase chain reaction to determine hepcidin mRNA levels in the liver ${ }^{13}{ }^{14}$ or polyclonal antibodies to quantify hepcidin levels in urine. $^{8}$ Ganz et al have developed an assay for measuring hepcidin levels in urine. The assay requires extraction of cationic peptides from urine followed by western blots. ${ }^{8}$ They raised polyclonal antibodies to synthetic hepcidin that had been refolded. Hepcidin contains eight cysteine residues which, when the molecule is correctly folded, results in a constrained bent hairpin structure. ${ }^{20}$ Attempts by other groups to refold synthetic hepcidin have been unsuccessful because of these cysteine residues. The urine assay is somewhat cumbersome and the mRNA assay requires a liver biopsy sample, neither lending themselves to automation.

In this issue of Gut, Kulaksiz and colleagues ${ }^{21}$ describe a competitive ELISA for measuring the level of pro-hepcidin and its application to patients with $\mathrm{HH}$, chronic renal insufficiency, and renal anaemia [see page 735]. They conclude that the pro-hormone form, pro-hepcidin, is most probably involved in regulation of iron metabolism in $\mathrm{HH}$, and that decreased levels could play an important role in the pathogenesis of $\mathrm{HH}$. The assay may also prove useful in investigating the variation in iron loading seen in patients who are homozygous for the $\mathrm{C} 282 \mathrm{Y}$ mutation in the HFE gene.

Rather than attempting to refold the entire hepcidin molecule, Kulaksiz et al raised antipeptide antibodies to sequences specific to pro-hepcidin (residues 28-47 of prohepcidin) and to the terminal 15 amino acids in the processed hepcidin. ${ }^{21}$ The latter antibodies will not differentiate between the 25 amino acid and the 22 and 20 amino acid forms that have been reported in urine and are thought to be degradation products. ${ }^{5}$ Using these antipeptide antibodies, Kulaksiz et al demonstrated that HepG2 cells express hepcidin, as do hepatocytes but not Kupffer cells, endothelial cells, or cells in the bile duct. ${ }^{21}$ The immunoreactivity was predominantly located in the periportal zones. At the subcellular level, hepcidin was concentrated on the basolateral membrane of hepatocytes. ${ }^{21}$ They also observed what could be hepcidin dimers on western blots. ${ }^{21}$

There are still many unanswered questions. We do not know what signals result in the increased synthesis of hepcidin by the liver or what the receptor is in the gut that responds to hepcidin. It is of course possible that hepcidin interacts directly with proteins such as the basolateral transporter ferroportin/IREGl and so controls the release of iron both from the duodenal enterocytes and macrophages. Patients with mutations in the ferroportin/IREGl gene (SLC40A1) have been described and present with a hyperferritinaemia that has an autosomal dominant pattern of inheritance. $^{22-25}$ As hepcidin is an acute phase protein it is synthesised to restrict the body's iron stores, to prevent this iron being requisitioned by invading bacteria, but this does not explain how it responds to the body's iron needs. It is possible that the link involves hypoxia.

\section{"It will be interesting to see how hemojuvelin contributes to iron homeostasis"}

The missing juvenile haemochromatosis gene product mapping to chromosome 1 may provide some of the missing links. The hepcidin gene is regulated both by CCAAT/ enhancer binding protein $\alpha(\mathrm{C} / \mathrm{EBP} \alpha)^{26}$ and interleukin $6{ }^{8}$ Neither of these genes map to chromosome 1. Very recently, a joint paper from the groups of Goldberg from Xenon Genetics Research and Papanikoloaou from Greece have described a gene they call hemojuvelin which maps to chromosome 1; this is clearly the HJV gene. ${ }^{27}$ The gene product is unlikely to be the hepcidin receptor as it appears to modulate hepcidin expression. ${ }^{27}$ Hemojuvelin is predicted to be a transmembrane protein having both an RGD (Asp-Gly-Asp) motif and a partial von Willebrand factor type D domain. ${ }^{27}$ As might be expected, it is expressed in both adult and fetal liver but also in heart and skeletal muscle. It will be interesting to see how hemojuvelin contributes to iron homeostasis.

\section{REFERENCES}

1 Fleming RE, Sly WS. Mechanisms of iron accumulation in hereditary hemochromatosis. Annu Rev Physiol 2002;64:663-80. 
2 Knutson M, Wessling-Resnick $M$. Iron metabolism in the reticuloendothelial system. Crit Rev Biochem Mol Biol 2003;38:61-88.

3 Finch C. Regulators of iron balance in humans. Blood 1994;84:1697-702.

4 Krause A, Neitz S, Magert HJ, et al. LEAP-1, a novel highly disulfide-bonded human peptide, exhibits antimicrobial activity. FEBS Lett 2000:480:147-50.

5 Park CH, Valore EV, Waring AJ, et al. Hepcidin, a urinary antimicrobial peptide synthesized in the liver. J Biol Chem 2001;276:7896-910.

6 Pigeon C, llyin G, Courselaud B, et al. A new mouse liver-specific gene, encoding a protein homologous to human antimicrobial peptide hepcidin, is overexpressed during iron overload. J Biol Chem 2001;276:781 1-19.

7 Shike H, Lauth X, Westerman ME, et al. Bass hepcidin is a novel antimicrobial peptide induced by bacterial challenge. Eur J Biochem 2002;269:2232-7.

8 Nemeth $E$, Valore EV, Territo $M$, et al. Hepcidin, a putative mediator of anemia of inflammation, is a type II acute-phase protein. Blood 2003;101:2461-3.

9 Nicolas G, Bennoun M, Devaux I, et al. Lack of hepcidin gene expression and severe tissue iron overload in upstream stimulatory factor 2 (USF2) knockout mice. Proc Natl Acad Sci USA 2001;998:8780-5.

10 Nicolas G, Bennoun M, Porteu A, et al. Severe iron deficiency anemia in transgenic mice expressing liver hepcidin. Proc Natl Acad Sci USA 2002;99:4596-601

11 Nicolas G, Chauvet C, Viatte L, et al. The gene encoding the iron regulatory peptide hepcidin is regulated by anemia. J Clin Invest 2002;110:1037-44.

12 Weinstein DA, Roy CN, Fleming MD, et al. Inappropriate expression of hepcidin is associated with iron refractory anemia: implications for the anemia of chronic disease. Blood 2002;100:3776-81.

13 Bridle KR, Frazer DM, Wilkins SJ, et al. Disrupted hepcidin regulation in HFEassociated haemochromatosis and the liver as a regulator of body iron homeostasis. Lancet 2003;361:669-73.

14 Gehrke SG, Kulaksiz H, Herrmann T, et al. Expression of hepcidin in hereditary hemochromatosis: evidence for a regulation in response to the serum transferrin saturation and to non-transferrin-bound iron. Blood 2003; 102:371-6.

15 Roetto A, Papanikoloau G, Politou M, et al. Mutant antimicrobial peptide hepcidin is associated with severe juvenile haemochromatosis. Nat Genet $2003 ; 33: 21-2$
16 Merryweather-Clarke AT, Cadet E, Bomford A, et al. Digenic inheritance of mutations in HAMP and HFE results in different types of haemochromatosis. Hum Mol Gen 2003; 12:2241-7.

17 Nicolas G, Viatte L, Lou D-Q, et al. Constitutive hepcidin expression prevents iron overload in a mouse model of hemochromatosis. Nat Genet 2003;34:97-101.

18 Muckenthaler M, Roy CN, Custodio AO, et al. Regulatory defects in liver and intestine implicate abnormal hepcidin and Cybrdl expression in mouse hemochromatosis. Nat Genet 2003;34:102-7.

19 Ganz T. Hepcidin, a key regulator of iron metabolism and mediator of anemia of inflammation. Blood 2003;102:783-8.

20 Hunter HN, Fulton DB, Ganz T, et al. The solution structure of human hepcidin a peptide hormone with antimicrobial activity that is involved in iron uptake and hereditary hemochromatosis. J Biol Chem 2002;277:37597-603.

21 Kulaksiz H, Gehrke SG, Janetzko A, et al. Pro-hepcidin: expression and cell specific localisation in the liver and its regulation in hereditary haemochromatosis, chronic renal insufficiency, and renal anaemia. Gut 2004;53:735-43.

22 Niajou OT, Vaessen N, Joosse M, et al. A mutation in SLC1 1A3 is associated with autosomal dominant hemochromatosis. Nat Genet 2001;28:213-14.

23 Montosi G, Donovan A, Totaro A, et al. Autosomal-dominant hemochromatosis is associated with a mutation in the ferroportin (SLC11A3) gene. J Clin Invest 2001;108:619-23.

24 Devalia V, Carter K, Walker AP, et al. Autosomal dominant reticuloendothelial iron overload associated with a three base pair deletion in the ferroportin 1 gene (SLC1 1A3). Blood 2002;100:695-7.

25 Roetto A, Merryweather-Clarke AT, Daraio R, et al. A valine deletion in ferroportin 1: a common mutation in hemochromatosis type 4 ? Blood 2002;100:733-4.

26 Courselaud B, Pigeon C, Inoue $Y$, et al. C/EBP $\alpha$ regulates hepatic transcription of hepcidin, and antimicrobial peptide and regulator of iron metabolism. J Biol Chem 2002;277:41163-70.

27 Papanikolaou G, Samuels ME, Ludwig EH, et al. Mutations in HFE2 cause iron overload in chromosome lq-linked juvenile hemochromatosis. Nat Genet 2004;36:77-82. 